Article

\title{
Conflict and Impacts Generated by the Filming of Discovery Channel's Reality Series "Naked and Afraid" in the Amazon: A Special Case in the Cuyabeno Wildlife Reserve, Ecuador
}

\author{
Carlos Mestanza *(-), Hilter Figueroa Saavedra, Isabel Domínguez Gaibor, \\ Manuel Abarca Zaquinaula, Rita Lara Váscones and Oswaldo Malla Pacheco \\ Escuela Superior Politécnica de Chimborazo, Extensión Norte Amazónica, Facultad de Recursos Naturales, \\ Puerto Francisco de Orellana, Orellana 51002, Ecuador; hfigueroasaavedra@gmail.com (H.F.S.); \\ norma.dominguez@espoch.edu.ec (I.D.G.); manuel.abarca@espoch.edu.ec (M.A.Z.); \\ rita.lara@espoch.edu.ec (R.L.V.); oswaldo.malla@espoch.edu.ec (O.M.P.) \\ * Correspondence: carlos.mestanza@espoch.edu.ec or cmestanza@ug.uchile.cl; Tel.: +593-998-830-801
}

Received: 28 November 2018; Accepted: 19 December 2018; Published: 21 December 2018

check for updates

\begin{abstract}
Conflicts and ecological impacts in natural protected areas can arise for various reasons. The behavior of social stakeholders in the face of conflict is the object of study. Their reactions can be varied according to the personal interests of the parties. Conflicts can cause changes in the communities, incomprehensibly affecting the environment and ultimately transforming their lives. Although the environmental impacts have generally been well studied in protected areas, after reviewing the literature, it was observed that very few studies exist on the local economic conflicts that frequently arise. The purpose of this study was to evaluate the socio-ecological conflicts and impacts generated by the filming of the American reality series Naked and Afraid, produced by the Discovery Channel in the Ecuadorian Amazon-a special case in the Cuyabeno Wildlife Reserve. The data was gathered from numerous primary sources, including field interviews with the regional stakeholders involved and a video analysis of the Discovery Channels' Naked and Afraid. The results of our study conclude several interesting insights into various social and ecological conflicts and their resulting impacts on the Cuyabeno Wildlife Reserve. The first of these concerns the high impacts mainly associated with biotic components in the Reserve. The second set of interesting findings are social conflicts that were caused by the discontent of the Indigenous communities in relation to royalties and compensations left by the filming.
\end{abstract}

Keywords: conservation conflicts; protected areas; economic compensation; reality series

\section{Introduction}

In many parts of the world, protected areas have become the main instrument of public policy for the conservation of biodiversity [1,2]. Although there are many sources of motivation to create these areas, in general terms, protected areas have been presented as a tool to stop the degradation of ecosystems caused by the economic activity of modern societies [3]. That is why the first conservationist efforts worldwide, based on the model of national parks in the United States of America, sought to exclude human populations and their economic activities from these areas [4]. However, conservation policies in the human settlements have been transformed, from emphasizing the isolated protection of landscapes to a broader and more inclusive approach, in which protected areas are seen as an instrument both to conserve and protect biodiversity, while at the same time enhance the socio-economic development of local populations [2,5]. 
Conflicts between wildlife, managers of protected areas, and local populations have long since arisen. The management models used in protected areas to achieve conservation objectives can be diverse, however, these will not avoid the presence of conflicts about use of and access to natural resources. Natural areas worldwide are facing serious problems, as a result of the human-wildlife conflict [6].

We are only beginning to understand the human-wildlife conflict and its impact on environmental functions, interactions with, and stability of an ecosystem in regard to its abiotic and biotic relationships. Current studies on conflicts between human-wildlife conflicts are increasing [1,3]. In Ecuador, for example, the state government is responsible for coordinating and controlling development of national and provincial importance, using state environmental planning policies [3]. Conflicts in conservation usually derive from larger societal issues, such as poverty and inequality, imbalances of power, and inappropriate governance processes in respect to ongoing development and economic growth.

These policies often result in conflict between the local communities and the authorities over the use and regulation of the ecosystem resources within the reserves [4]. When talking about conservation and conflicts, it is necessary to ask, "Is the conflict between ecosystem conservation and human land use inevitable, or can they be reconciled to mutually benefit both?" Some legislations worldwide accept that rural communities are the moral owners of natural resources from their lands. While that recognition is essential, the crucial issue, however, questions the most adequate manner in which these communities acquire and implement management and control over these resources $[5,6]$ ?

Currently, Ecuadorian law requires any work, project, or activity to leave royalties or compensation for locals. However, when the economic benefits or compensations are poorly managed by the leaders or representatives of communities, it will not help the conservation of a protected area $[7,8]$.

Naked and Afraid is an American reality series on television (TV) that airs on the Discovery Channel, filmed in the Cuyabeno Wildlife Reserve (Figure 1) of Ecuador in the year 2016.

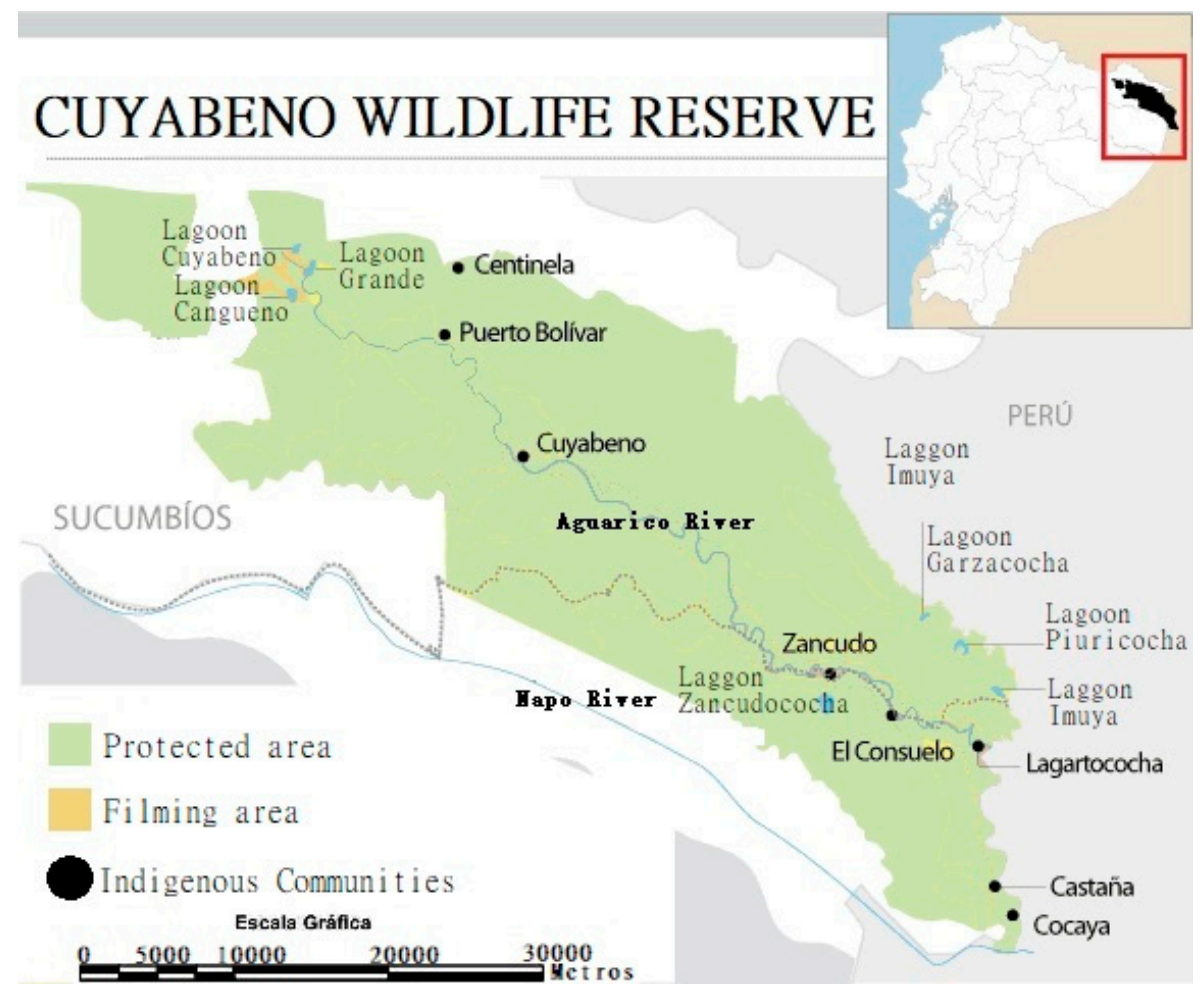

Figure 1. Location map, Cuyabeno Wildlife Reserve. 
The synopsis is based on a group of 12 experts put into a survival situation that has never been attempted before. The goal is to survive in hostile environmental conditions for 40 days. Each survivalist is only allowed to bring one or two helpful item(s) of their choosing, making it exponentially more difficult than anything that's ever been tried in the past [9]. The show bends the definition of reality just as any other survival show before it, and thus what you think is real might not actually be happening at all, or at least to some degree [10]. Reality TV shows are among the most popular types of TV programs worldwide [11]. These TV series have an important role in terms of their influence on the audience; such productions are very popular in Latin America by those who aim to broaden their target audience [12].

The methodology used in the present study has been successfully used in many tourist areas within the National Systems of Protected Areas. In our case, the Leopold matrix evaluation focused on the environmental impacts generated by the Discovery Channel within the Cuyabeno Wildlife Reserve. The application of this method will lead to better planning and management of tourism activities in protected areas. In addition, there are two possible scales for the application of this methodology. On the one hand, it is possible to consider the protected area in its entirety and evaluate the magnitude of the impacts. On the other hand, it could be applied locally, evaluating the impacts in specific areas where land use activities are carried out [1,7]. In this study, the methodology was applied at a local scale to conglomerate a complete record of the filming activity.

\section{Approaches Towards the Understanding of the Conflicts and Impacts in Protected Areas}

\subsection{Socio-Environmental Conflicts in Ecosystems}

The use of natural resources in protected areas has given rise to social conflicts. Such conservation conflicts or socio-environmental conflicts can be defined as situations that occur when two or more stakeholders hold opposing interests, perceptions, opinions, or emotions on a given objective $[8,11]$. This definition recognizes that conflicts can occur between human beings and that in the context of protected areas, conflicts may arise when the conservation interests of one of the parties are threatened by the position of those with a different vision. Although there is no conflict without subjective opinions, the term socio-environmental conflict emphasizes the social dimension arising from environmental problems that are sometimes overlooked [13]. In this way, the term socio-environmental conflict recognizes the need to characterize other aspects of conflictual situations, such as the distribution, access, and ownership of natural resources [14].

Perhaps there is nothing more prevalent in interpersonal relationships than the arising of conflicts in general terms. Social conflict refers to the process of contentious interaction around resources, power and status, beliefs, and other preferences or desires [13]. The goal of the groups or people in conflict can range from merely achieving the acceptance of a particular preference or ensuring preferential access to a resource, to the point of hurting or eliminating opponents [14,15]. Counter positions do not stop at the material level, since there are symbolic elements of identity and satisfaction of basic needs, which are related to natural resources and geography. These interests shape the positions of the social stakeholders in a dispute $[11,16]$.

In recent times, protected natural areas have greatly suffered from anthropogenic influences, and for this reason it is necessary to implement new conservation techniques for protected areas. The surface of protected areas worldwide in recent years has augmented to the point that currently $14 \%$ of the earths land surface has some form of protection $[15,16]$. Legislation in a protected area can generate detrimental conflicts when it is not managed correctly. The diverse governmental actors and the local population can feel negatively impacted by the access and use of natural resources in protected areas $[10,14]$. Mismanaged conflicts in protected areas can often make the situation worse than it started out $[14,15]$. 
The problems and conflicts that arise in natural protected areas require solutions derived from multidisciplinary approaches honoring ethical values, where decisions and discussions are conducted in an adaptive and transparent manner [16]. Access and use of natural resources in protected areas generate frequent conflicts among social stakeholders. Several publications consider it necessary to involve local communities in management decisions. [17,18]. Currently, the field of conservation seeks to implement integration models that meet the needs of the main stakeholders in protected areas, in order that the conservation objectives are not affected by potential conflicts, which almost always arise due to economic disputes in relation to compensation or royalties. [9,16,18].

The establishment of protected areas has generated some conflicts due to complex reasons, including restriction of certain activities, limitations on the usufruct of natural resources, economic disputes, and lack of incorporation of local communities in decision-making. These conflicts put at risk the very viability of these areas as spaces for the regeneration of ecosystems and for sustainable development $[10,13]$.

Generally, the causes of socio-environmental conflicts go beyond simple differences between stakeholders being strongly linked to power relations and values related to the socio-cultural history of a territory $[10,16]$. Conflicts are often associated with instability, unrest, violence, stalemate in relationships, and lack of cooperation. However, because conflict is primarily a process of social change, it can be understood as a transforming medium, through which positions are made evident [19], disagreements are aired, differences are expressed, identities are demarcated socially and personally, and creative and lasting resolutions are reached, ultimately balancing the differences of power in society $[13,20]$. Due to the prevalence of conflict situations in protected areas, it is necessary to carefully investigate the reasons why disputes erupt and understand the socio-environmental impacts of them.

Protected areas, when well managed and when they address objectives that are achievable, provide multiple benefits, protecting landscapes while preserving biodiversity and essential ecosystem services [20]. Investigators have demonstrated the role of protected areas for their ability to reduce habitat loss and maintain terrestrial and marine populations. However, the rapid growth of protected areas in the last half of the 20th century created situations of conflict with the interests of local populations $[10,21]$. In this period, there has been a growing awareness of the rights of the local populations and their role in the governance of their territories, as well as growing evidence of their contribution to poverty alleviation and economic development in and around the protected area. Political corruption and armed conflict often affects protected areas in many parts of the world, rendering the efforts of managers ineffective [22].

\subsection{Socio-Economic Impacts on Ecosystems}

The environmental impact is an alteration in the environment that changes the standard conditions of evolution. In this sense, both anthropogenic activities, as well as the results of meteorological phenomena, are linked to the transformation of resources and produce changes in the environment. However, it is necessary to emphasize the nature and magnitude in which such actions affect certain territories.

In recent years, the degradation of the natural environment has been evident due to the development of anthropogenic activities. Exploitation of natural resources in protected areas has caused various detrimental environmental impacts to vital components and functions of the ecosystems $[23,24]$. With a perspective contrary to the preservation of resources, certain human activities have favored the spontaneous commercialization of natural spaces, that have possible repercussions for the environment, despite such conservation efforts. In this context, recreational practices and intensive tourism in rural areas have allowed the irrational use of natural resources, with the assumption of sustainable and low environmental impacts on the physical and social conditions of the regions $[25,26]$. 
As a result, the development of activities in protected areas has increased the fragility of ecosystems. Thus, it is necessary to identify favorable or adverse characteristics that generate environmental impacts; first, defining tactics related to the improvement of natural resource conditions, and then characterizing the adverse effects impacting environmental conservation. Regarding this last perspective, the impacts can be observed directly when there is a total or partial loss of a particular resource (such as deforestation or the extinction of a species of flora or fauna), or indirectly by external risks to a determined space $[19,27]$.

The activity carried out in protected areas, such as ecological tourism, can cause various positive environmental impacts. Such benefits or forms of compensation can arise by raising awareness on appropriate usage of natural resources for social stakeholders, while the massive concentration of activities will have a negative impact on the carrying capacity of the site and the existing biodiversity. The degree of intensity of such environmental impacts depends on a wide range of variables, such as the character function, cause-effect relationships, the moment of manifestation, the interrelation of actions and alterations, extension, persistence, and their impacts on the capacity for ecosystem recovery.

Creating protected areas shows to be the predominant method for conserving biodiversity, however, tourist ingression can threaten their conservation value. Various land use activities generate different types of impacts with varying degrees of severity on ecosystems and their function. These various factors can include varying pollution levels by noise, air, water, and light; ecological disturbance; damage and death of plants and animals; soil compaction and loss; and the potential for the spread of weeds and pathogens. Eco-tourism should not be viewed as a panacea, nor an alternative for land use and management of protected areas, particularly in a country like Ecuador. The appropriate use of natural resources in or around pristine areas must take into account the funds needed to develop, maintain, and administer tourism services that minimize negative impacts on the environment.

\section{Materials and Methods}

\subsection{The Study Area}

The Cuyabeno Wildlife Reserve is one of the 56 protected areas of Ecuador. It is a strategic protected area that houses unique ecosystems representative of the Amazon region. It is located northeast of the Ecuadorian Amazon Basin in the provinces of Sucumbíos and Orellana, bordering Colombia to the north, and Peru to the east. This area consists of an estimated 600,000 hectares, comprising of around 12\% of Ecuador's protected land [28]. Within the reserve live the Indigenous nationalities of the Siona, Secoya, Cofán, Kichwa, and Shuar. The reserve is made up of the largest lacustrine system in the country, with high levels of biodiversity recognized worldwide and is considered a sanctuary for wildlife [29,30]. One of the leading conservation objectives is the preservation of natural ecosystems and susceptible species, so the land use actions carried out within it and its area of influence are aimed towards sustainable management of wildlife, environmental education, ecosystem restoration, and ecological tourism.

During the 20th century, the reserve underwent several changes. Within the Cuyabeno Wildlife Reserve, it is estimated that there are around 1320 species of fauna: 165 mammals, 493 birds, 96 amphibians, 91 reptiles, and 475 fish; and more than 12,000 species of plants. Also, the reserve has the record for the highest diversity of tree species per hectare in the world. [29]

\subsection{Methods}

The evaluation of land use impacts in protected wild areas is based on the identification of vulnerable ecosystem components and external pressures of the activities that are carried out [30,31]. The method used in the present investigation has been widely used in various environmental impact assessments in order to identify the main pressures derived from anthropogenic activities. [32]. In this study, the Leopold matrix was taken as a basis for its ease in providing 
a methodological framework for avoiding arbitrariness that allows for adaptivity to a wide variety of circumstances $[33,34]$. This basis allowed us to implement an optimal tool to determine the environmental impacts caused by the filming of the Discovery Channels' reality series Naked and Afraid in the Cuyabeno Wildlife Reserve, Amazon Region, Ecuador.

The Leopold matrix evaluation of environmental impacts by anthropogenic activities in protected areas shows five main advantages over other methods: (1) Its execution does not require experts, which provides accessibility to diverse stakeholders involved in or impacted by the management or use of protected areas; (2) potential and historical impacts can be evaluated; (3) it incorporates the perception of experts connected to the environmental components of the study area; (4) it does not consider subjective perceptions of the users, but prioritizes the physical environmental conditions; (5) it is an adaptable and practical tool that can be easily used to guide environmental management and prevent deterioration.

\subsection{Evaluation Process}

Step 1: Identification of Anthropogenic Pressures

The first process consisted of identifying the activities generated by the filming of the Discovery Channel's reality series Naked and Afraid in the protected area of Cuyabeno. In this study, we reviewed the management plans, as well as conducted interviews with reserve participants to compile a complete list of filming activities and conflicts that occurred. The interviews were conducted using a semi-structured approach [35] considering two aspects: (1) Guidelines about the interview were sent by email, then the interviewees were contacted by telephone to schedule a face-to-face appointment; (2) during the appointment, semi-structured interviews were conducted to receive additional comments about the impacts and conflicts generated.

\section{Step 2: Selection of Evaluation Components}

For a simplified study of the ecological and anthropogenic system of the protected areas, six components of consideration were developed: two abiotic (water and soil), two biotic (flora and fauna), and economic and social components. However, it is important to note that the difficulty in identifying the ecological and anthropogenic components can be complex, depending on the ecosystem characteristics of the study area.

Step 3: Identification and Description of Impacts

Following the completion of steps 1 and 2, we proceeded to build a Leopold pressure-component matrix. This matrix allowed us to identify and describe the anthropogenic pressures for each component and ultimately characterize their impacts. This vital process was based on consultation $[30,36]$ to a group of experts in ecological related practices (Figure 2). The technique and tools for obtaining expert opinions are described below.

Step 4: Scheme to Evaluate the Magnitude of the Environmental Impacts

To determine the magnitude of the impacts in the study area, the level of severity was considered via analyzing the intensity of these anthropogenic pressures, the vulnerability of the components, and the management capacity of the administrators in the protected area to prevent possible impacts. The severity and vulnerability of the components under study are related to the magnitude of the impact and management capacity. The magnitude of the impacts are related to the frequency and scope of the activities. The degree of vulnerability of the components of the ecosystem depend on how sensitive they are. The management capacity of the protected area depends on the available resources in topics such as legislation policies, and the required human and economic resources. The magnitude of the impacts detailed above was analyzed by the second group of experts, who were deeply involved with the components of the study area in Cuyabeno. Three levels of impacts were used to determine intensity levels of impact (low, medium, and high) as seen in Table 1. 


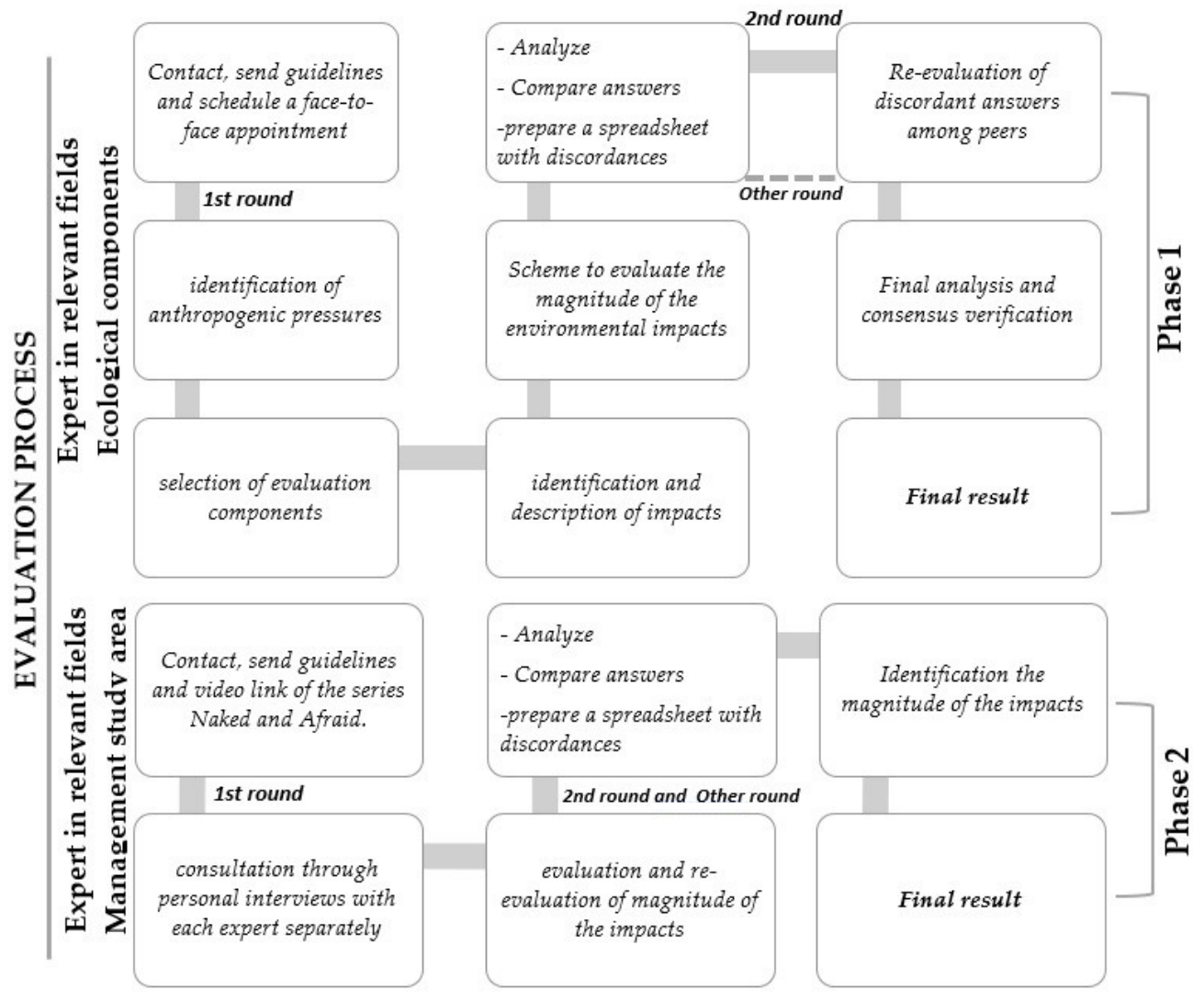

Figure 2. Method used for consulting experts.

Table 1. Description of the magnitude of impacts.

\begin{tabular}{cl}
\hline High & $\begin{array}{l}\text { Those that are incompatible with conservation. Their presence would raise the prohibition of use } \\
\text { or substantially modify the activities. }\end{array}$ \\
\hline Moderate & Those that can be compatible with conservation, after implementing management measures. \\
\hline Low & Compatible with conservation and susceptible to natural regeneration in the absence of activities. \\
\hline
\end{tabular}

\subsection{Expert Consulting}

As detailed above, the identification of impacts (Step 3) and the evaluation of the magnitudes (Step 4) were carried out by consulting experts. Similarly, the contributions and knowledge were incorporated in Steps 1 and 2. In the analysis process using the Delphi method, analysis and debate were sought on the pressures and impacts to each component under study [37]. The analysis with experts used two phases, the first being consultation on ecological components and the second being management in the study area (Figure 2).

Phase 1

The first group of experts was consulted with the objective of identifying and describing the impacts (Step 3). The members of this group were experts from different sectors, with at least four years of experience working in fields related to conservation and management of the natural environment, and preferably having postgraduate studies (Table 2). The consultations took two rounds to compare opinions and resolved disagreements among peers (Figure 2). A consensus matrix was obtained that incorporated all the impacts and their descriptions. 
Table 2. Selected experts were consulted to develop the impact and conflict assessment in Cuyabeno Wildlife Reserve. The specialists name, profession, and relation to the area are provided.

\begin{tabular}{cccc}
\hline Phase & Specialist & Profession & Relation to the Area \\
\hline \multirow{4}{*}{1} & Gonzalo Muñoz & PhD. in Bio. Sci & Professor-Spain \\
& Paúl Mestanza & Tourism, researcher & Director local NGO \\
& Confidential & Technical & Local area technical \\
& Jairo Alvarez & Local actor & Proprietary lodge \\
& Neiser Toro & Local actor & Protect area guide \\
2 & Fabian Goyes & Local actor & Community leader \\
& Confidential & Ranger & Ranger with wide experience \\
& Confidential & Master in Env. Sci. & Ex Director protect area \\
\hline
\end{tabular}

Phase 2

To execute the scheme (Step 4) on the magnitude of the conflicts and impacts, the second group of experts was consulted. A link [38] was sent to the experts of the video of the series being studied, Naked and Afraid. The focus of this second group of experts was their specialized knowledge about the study area of Cuyabeno Wildlife Reserve and its management (Table 2). We conducted a consultation through personal interviews with each expert separately. The experts during the interview marked an " $X$ " on the magnitude of the impact on each component evaluated and were asked to add observations related to the subject of the study. Two rounds of questions and answers were conducted, as in the first phase. In the end, the various magnitudes of the impacts associated with each ecological component were identified.

\section{Results}

The study allowed the evaluation of the main impacts and conflicts generated by the filming of the reality series Naked and Afraid by the Discovery Channel in the Cuyabeno Wildlife Reserve, Amazon Region, Ecuador. We identified six main activities carried out in the area: Hiking in the jungle, canoe trips, camping construction, alimentation, other services, and contact with social stakeholders. (Table 3).

Table 3. Description of the activities carried out in the filming process within the reserve.

\begin{tabular}{cl}
\hline Activities & \multicolumn{1}{c}{ Description } \\
\hline Hiking in the jungle & Hiking in unauthorized areas. \\
Canoe trips & $\begin{array}{l}\text { Navigation in rivers by canoe with combustion motors. Canoes were used to } \\
\text { transport survivors and film crew. }\end{array}$ \\
Camping construction & Shelters were built from the raw material in the protected area. \\
Alimentation & To supply food, survivors had to seek energy in local plants and animals. \\
Other Services & The needs of fire and human needs were based on the environment and taken \\
from the raw materials of the area. & The actors and filming staff interacted with the community and service providers. \\
\hline
\end{tabular}

We identified fourteen types of socio-environmental impacts on the six identified components (biotic, abiotic, economic, and social components) caused by these six main activities carried out in the filming process (Table 4). The economic and social aspects are analyzed by their relation to the activities during the filming of the series. These impacts are the main axes for the conflicts encountered. Out of the six analyzed activities, contact with social participants was detected as the only activity that did not generate substantial impacts on biotic components. However, the remaining five activities generated a surprising impact on both biotic and abiotic components of the Cuyabeno ecosystem. Out of the six impacted components studied, the soil in regard to the abiotic components and the social components resulted in having the highest number of detrimental impacts from the filming activities (6), followed by fauna, flora, and water (5) and, finally, economic impacts (1) (Table 4). 
Table 4. Impacts associated with the impacted components identified during the filming of the Discovery Channel's reality series Naked and Afraid in the Cuyabeno Wildlife Reserve.

\begin{tabular}{|c|c|c|c|c|c|c|}
\hline \multirow{3}{*}{ Activities } & \multicolumn{6}{|c|}{ Component } \\
\hline & \multicolumn{2}{|c|}{ Biotic } & \multicolumn{2}{|c|}{ Abiotic } & \multicolumn{2}{|c|}{ Other } \\
\hline & Fauna & Flora & Soil & Water & Economic & Social \\
\hline $\begin{array}{l}\text { Hiking in the } \\
\text { jungle }\end{array}$ & Perturbation & $\begin{array}{c}\text { Loss } \\
\text { Pollution }\end{array}$ & $\begin{array}{l}\text { Compaction } \\
\text { Erosion }\end{array}$ & $\begin{array}{l}\text { Pollution } \\
\text { (SW) }\end{array}$ & & Perturbation \\
\hline Canoe trips & Perturbation & $\begin{array}{c}\text { Loss } \\
\text { Pollution }\end{array}$ & $\begin{array}{l}\text { Compaction } \\
\text { Erosion }\end{array}$ & $\begin{array}{l}\text { Pollution } \\
(\mathrm{M}, \mathrm{SW}, \mathrm{E})\end{array}$ & & Perturbation \\
\hline $\begin{array}{l}\text { Camping } \\
\text { construction }\end{array}$ & Perturbation & $\begin{array}{c}\text { Loss } \\
\text { Pollution }\end{array}$ & $\begin{array}{l}\text { Compaction } \\
\text { Erosion }\end{array}$ & & & Perturbation \\
\hline Alimentation & Loss & Loss & $\begin{array}{c}\text { Compaction } \\
\text { Erosion }\end{array}$ & $\begin{array}{l}\text { Pollution } \\
(\mathrm{SW}, \mathrm{E})\end{array}$ & & Perturbation \\
\hline Other services & $\begin{array}{l}\text { Perturbation } \\
\text { Loss }\end{array}$ & $\begin{array}{c}\text { Loss } \\
\text { Perturbation }\end{array}$ & Contamination & $\begin{array}{l}\text { Pollution } \\
(\mathrm{SW}, \mathrm{E})\end{array}$ & & $\begin{array}{l}\text { Pollution } \\
(S W, E)\end{array}$ \\
\hline $\begin{array}{l}\text { Contact with } \\
\text { social actors }\end{array}$ & 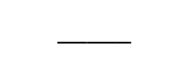 & 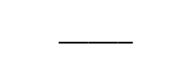 & $\begin{array}{l}\text { Compaction } \\
\text { Erosion }\end{array}$ & $\begin{array}{l}\text { Pollution } \\
\quad(S W)\end{array}$ & Loss & $\begin{array}{c}\text { Perturbation } \\
\text { Conflicts }\end{array}$ \\
\hline
\end{tabular}

SW: Solid wastes. E: Effluents. M: Motor.

The identified impacts and conflicts in the Cuyabeno Wildlife Reserve showed to be very detrimental during and after the filming of the reality series Naked and Afraid by the Discovery Channel (Table 5). In the study area, fourteen different socio-environmental impacts were identified, four observed to have a very high impact, two relating to the fauna components (perturbation by people and loss by damage or death), one relating to the flora component (loss by damage or removal), and one in relation to the economic component (low income and compensation). Seven impacts of medium magnitude were identified; five being relating to the soil component (erosion by human treading, erosion by camping sites, compaction, erosion, and pollution by effluents), one in the water component (pollution by motors), and one in the social component (perturbation by people). Three impacts of low magnitude were identified in respects to the flora, water, and social components (pollution by chemical and solid wastes). In general, considering all activities performed in the Cuyabeno Wildlife Reserve by the filming of the Discovery Channel's reality series Naked and Afraid, it was recognized that $50 \%$ of the activities had a medium impact, $28 \%$ had a high impact, and $22 \%$ had a low impact on the six observed components.

Table 5. Main results of the magnitude of the impacts and conflicts in the Cuyabeno Wildlife Reserve.

\begin{tabular}{ccc}
\hline Component & Impact & Magnitude \\
\hline \multirow{2}{*}{ Fauna } & Perturbation (Figure 3c) & High \\
& Loss by damage or death. (Figure 3b) & High \\
Flora & Loss by damage or removal (Figure 3a) & High \\
& Pollution by chemical and solid wastes & Low \\
& Erosion by human treading & Medium \\
Soil & Erosion by camping sites & Medium \\
& Compaction & Medium \\
& Erosion & Medium \\
Water & Pollution by effluents & Medium \\
Economic & Pollution by chemical and solid wastes & Low \\
& Pollution by motors & Medium \\
Social & Low income and compensation & High \\
& Perturbation & Medium \\
Results & Pollution by chemical and solid wastes & Low \\
& Low impact & $22 \%$ \\
& Medium impact & $50 \%$ \\
& High impact & $28 \%$ \\
\hline
\end{tabular}




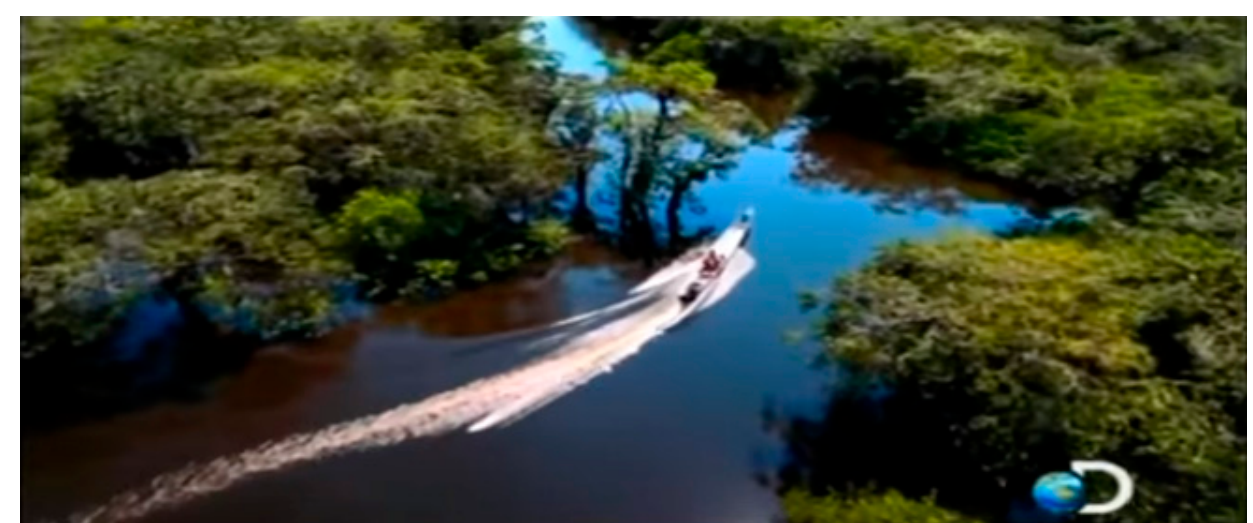

(a) Flora loss by damage or removal, soil erosion, and compaction by human treading and camping sites.

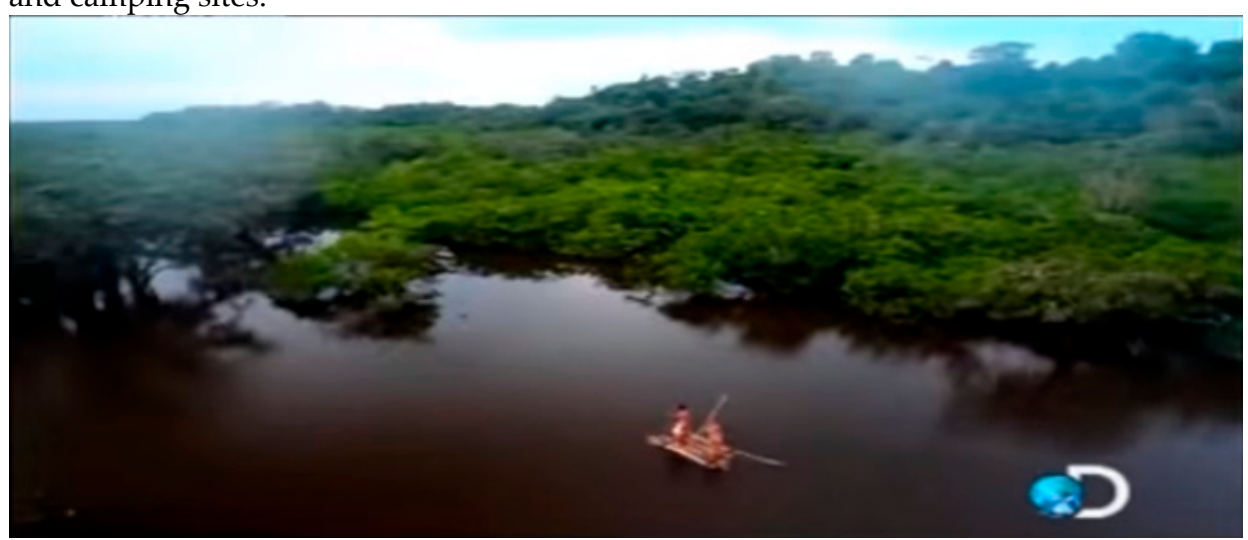

(b) Fauna perturbation by people and loss by damage or death.

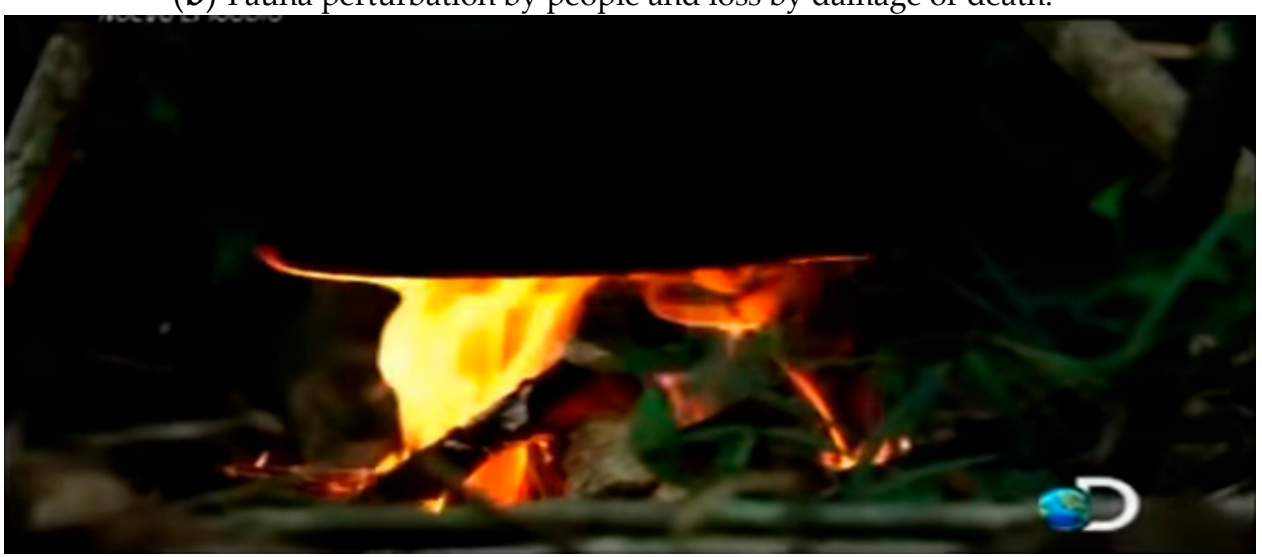

(c) Perturbation by people (fire).

Figure 3. Impacts generated by the filming of reality series Naked and Afraid by the Discovery Channel in Supplementary (source: https: / www.youtube.com/watch?v=9hffDFaYYvg\&t=2309s).

The results of our study suggest several interesting insights into impacts and conflicts generated by the filming of reality series Naked and Afraid by Discovery Channel. The first of these concerns are the high impacts mainly associated with the biotic components. In the process of filming the series, the environmental management plan of the reserve was violated. The filming activities took place outside the public zones, where the participants caused detrimental impacts to the fauna and flora when performing their survival activities (habitat and alimentation). In the economic aspect, the lodge was very negatively impacted, as the film series occupied all of their rooms for two months, which at that time no tourists were received. One owner said, "For me, after two months, it was like starting the business from scratch. It took me a long time to get back the number of tourists I had before filming, and our income took a toll". 


\section{Discussion}

This suggests that the objectives of management and conservation established for the Cuyabeno Wildlife Reserve may not be entirely implemented or achieved after observing the impacts of these activities, such as the ones analyzed in this study. Results showed that $50 \%$ of the total identified impacts had high magnitudes of impact on the soil abiotic components, followed by the water and social components. This was mainly because of the "frequency of pressure" criteria. In Ecuador, this study pioneers the important topic of conflicts in relation to filming activities. In other countries in Africa, North America, and Asia, reality series are constant activities in their protected areas. As the Ecuadorian Amazon is a hotspot for biodiversity of flora, fauna, and Indigenous people, it is necessary to propose new, appropriate policies on the permitted use of protected areas for activities in the filming industry in order to regulate and ensure the conservation objectives.

Generally, the central government is responsible for issuing permits for filming activities. When asked about the conditions of the permits granted for the filming by the Discovery Channel, the corresponding administrators and managers were very vague and unable to provide specific information about the terms of the permit granted to the Discovery Channel. A document was presented in the offices of the competent environmental authority that issued the filming permits, requesting to make public the terms in which the filming was authorized as a response to an astounding number of environmental impacts after the filming of the series. We wanted to know if these detrimental impacts counteracted the established environmental management plan, and any type of royalties or compensation were proposed. After eight months of waiting, we were never notified about the request.

Furthermore, social conflicts became apparent by the discontent of the Indigenous communities in relation to no royalties or compensation left to the communities by the filming company. There were times when the Indigenous people entered the filming areas by force to protest, calling attention to the managers of the protected area. The Reserve administrators violated the management plan, and in certain occasions, even obstructed the Indigenous people from their protests to stop the filming activities. Offers were finally made through the delivery of goods, such as canoes and motors, as part of the royalties and compensation. This brought calm to the conflicts, however the natives continue to express their dissatisfaction with the actions of the administrators.

Studies on impacts and conflict in protected areas suggests that it will not only cause percussions on the ecosystem and wildlife, but also socially between the native inhabitants and external stakeholders. Conflicts in protected areas is a component that will always be present. These studies have been extensive in the last decades, but it has not been possible to reach consensus on the origins of conflicts and their possible solutions $[39,40]$. Our study suggest that perception of Indigenous communities about impacts can often be overlooked or ignored when economic conflicts exist. Economic interests in protected areas can divert managers and stakeholders away from compliance with conservation objectives, for which the protected area was created.

The present methodology could be adapted following the proposed steps for anticipation of future activities and their potential environmental impacts. Thus, this methodology can be aligned with conservation goals to evaluate the pertinence of filming of reality series in protected areas. Overall, these results could be useful inputs for management and implementation of policies for public use in protected areas, with the aim of minimizing future environmental impacts.

The methodology can be applied to estimate the environmental impact of different productive, social, or cultural activities performed in protected areas. To do this, impacts should be identified appropriately, and the criteria for estimating the magnitude of such impacts should be adapted following the proposed methodology. In order to successfully apply these methods, it is suggested to consider the inclusion participants from different sectors and disciplines. This is necessary to avoid bias in the results, since, as previously mentioned, the results depend on the perception of those that apply it. 
The perspective of the stakeholders regarding the mentioned conflicts and impacts may vary according to their interests [41,42]. Nevertheless, with this denotation it is difficult to understand the genesis of conflicts or the magnitude of their impacts. Authors such as Büscher [43] argue that conflicts should not be analyzed lightly, but rather as a set of serious conflicts caused for economic interests that if not managed correctly, can seriously affect the ecological and socio-cultural components of an ecosystem. However, it must be recognized that in most cases, the impacts and conflicts generated in a protected area may be the result of a poorly-designed conservation strategy. Therefore, it is necessary to modify or implement new policies aimed at proper use and exploitation of resources within and around protected areas. Here a challenge arises to select appropriate strategies that allow proper management of protected areas, that in the face of conflict can act on their structural causes (that is, the compensations and economic royalties). Not acting on these issues will end up compromising the integrity of a protected area, breaching the objectives for which it was created. Ultimately, what takes place is nothing more than the deterioration of an ecological space for the economic interests of few.

\section{Conclusions}

The empowerment of communities to assume greater responsibility should be considered for assessing, monitoring, and controlling development proposals, and be present to negotiate settlements of conflicts in order to establish sustainable, long-term visions for their communities.

The reality of the management and conservation in protected areas in the presence of economic compensations for activities, like the filming of reality series, is that the stakeholders are confronted with human-wildlife conflicts of interest, and the management can prove ineffective and negatively affect conservation of natural and anthropogenic components.

The compensations and royalties offered by the directors of the reality show Naked and Afraid by the Discovery Channel (income and publicity of the site) for social stakeholders (owners of the lodge, Indigenous community) at the beginning may seem interesting and draw the attention of the actors to such a point that access is permitted, allowing their activities. However, our results show unexpectedly high socio-environmental impacts as a direct result from the filming activities in the Cuyabeno Wildlife Reserve. When reviewing the series on television, all the information regarding the place and communities was changed, preventing viewers from knowing the actual location of the filming. The presence of tourists in the lodges used for the filming decreased significantly. The areas used presented important damage from loss of flora and fauna, and as a result, this environmental disturbance made it impossible for future sightings of animals for tourism.

As conservation emerges as a new site of speculative capital accumulation $[43,44]$, the use of natural spaces for adventure and survival activities may have, as in our study, detrimental impacts not just on human communities, but on the wildlife as well. This study seeks to convey to readers that not all activities in protected areas are in harmony with the existing conservation efforts. The activities that offer royalties bring conflicts between administrators, social actors, and wildlife. This can, however, contribute to developing a more expansive view of justice in Indigenous communities.

Biotic and abiotic components continue to suffer depletion because the state has failed to properly manage the Cuyabeno Wildlife Reserve. This ruling has led to the fact that in the reserve, lucrative activities are carried out without proper control, ultimately leading to the tragedy of the commons.

Nature is a finite resource, so as human populations grow, our land use and extraction needs compete with protected areas. In these situations of keen competition, wildlife is the first to suffer, then the forests, and finally the soils. Curiously, wildlife conservation advocates have not caught on to the growing realization and consensus that acknowledge that the only hope of sustainable resource use and sustainable development lie with an integrative participation with locals. Success will only come once ownership and management of resources is dynamically performed in the communities. 
To understand in depth the causes and processes behind conflicts, it is necessary to identify and conceptualize the stakeholders involved, elucidating their interests, motives, and strategies on resources, be they local communities, civil society organizations, government officials, business people, or academics.

Ultimately, it is recommended for future projects or related actions in protected areas to include the social participation of local communities when discussing activities, royalties, or compensation. It is important to incorporate a proper budget to evaluate generated impacts and possible solutions to mitigate their impact. In regard to the evaluation and monitoring of the protected area for actions, such as tourism or resource extraction, it is highly recommended that a third non-profit organization or an academic representative collaborate in such analysis.

Supplementary Materials: The public video of reality series Naked and Afraid of the Discovery Channel in the Amazon: A special case in the Cuyabeno Wildlife Reserve, is available at https://www.youtube.com/watch? $\mathrm{v}=$ 9hffDFaYYvg\&t=2309s.

Author Contributions: C.M. designed the study and participated in all phases of conceptualization, methodology, investigation, writing—original draft, and writing-review \& editing; formal analysis, H.F.S., I.D.G., M.A.Z., R.L.V., and O.M.P.

Funding: This research received no external funding.

Acknowledgments: This work is a contribution to the Escuela Superior Politécnica de Chimborazo, Extensión Norte Amazónica, Puerto Francisco de Orellana, Orellana, for the opportunity it offers for personal development as a researcher. Special thanks to the professionals and social actors for their time. A sincere thanks to Lexie Gary Gropper for her contributions, founder of the organization Amisacho that focuses on raising awareness about the restoration of the Amazon rainforest by providing the community with educational opportunities, permaculture crops, and natural products to maintain human health and forests.

Conflicts of Interest: The authors declare no conflict of interest.

\section{References}

1. Rakshya, T. Living with Wildlife: Conflict or Co-Existence. Acta Ecol. Sin. 2016, 36, 509-514. [CrossRef]

2. Anand, S.; Radhakrishna, S. Investigating Trends in Human-Wildlife Conflict: Is Conflict Escalation Real or Imagined? J. Asia-Pac. Biodiver. 2017, 10, 154-161. [CrossRef]

3. Dickman, A. Complexities of Conflict: The Importance of Considering Social Factors for Effectively Resolving Human-Wildlife Conflict. Anim. Conserv. 2010, 13, 458-466. [CrossRef]

4. Baynham-Herd, Z.; Redpath, S.; Bunnefeld, N.; Molony, T.; Keane, A. Conservation Conflicts: Behavioural Threats, Frames, and Intervention Recommendations. Biol. Conserv. 2018, 222, 180-188. [CrossRef]

5. Lu, H.; Siemer, W.; Baumer, M.; Decker, D. Exploring the Role of Gain Versus Loss Framing and Point of Reference in Messages to Reduce Human-Bear Conflicts. Soc. Sci. J. 2018, 55, 182-192. [CrossRef]

6. Madalina, O. Conflict Management, A New Challenge. Procedia Econ. Financ. 2016, 39, 807-814. [CrossRef]

7. Lonn, P.; Mizoue, N.; Ota, T.; Kajisa, T.; Yoshida, S. Evaluating the Contribution of Community-Based Ecotourism (CBET) To Household Income and Livelihood Changes: A Case Study of the Chambok CBET Program in Cambodia. Ecol. Econ. 2018, 151, 62-69. [CrossRef]

8. Mooser, A.; Anfuso, G.; Mestanza, C.; Williams, A. Management Implications for the Most Attractive Scenic Sites Along the Andalusia Coast (SW Spain). Sustainability 2018, 10, 1328. [CrossRef]

9. Discovery Channel. Available online: https://www.discovery.com/tv-shows/naked-and-afraid-xl/ (accessed on 28 June 2018).

10. Ranker. Available online: https://www.ranker.com/list/naked-and-afraid-fake/beth-elias (accessed on 28 June 2018).

11. Patino, A.; Kaltcheva, V.; Smith, M. The Appeal of Reality Television for Teen and Pre-Teen Audiences. J. Advert. Res. 2011, 51, 288-297. [CrossRef]

12. Yildirim, Y.; Aydın, K. The Role of Popular TV Series and TV Series Characters in Creating Brand Awareness. Procedia Soc. Behav. Sci. 2012, 62, 695-705. [CrossRef] 
13. UN Environment World Conservation Monitoring Centre (UNEP-WCMC); International Union for Conservation of Nature (IUCN). Protected Planet Report 2016; UN Environment World Conservation Monitoring Centre (UNEP-WCMC); International Union for Conservation of Nature (IUCN): Cambridge, UK, 2016; ISBN 9789280735871.

14. García-Frapolli, E.; Ayala-Orozco, B.; Oliva, M.; Smith, R. Different Approaches Towards the Understanding of Socio-Environmental Conflicts in Protected Areas. Sustainability 2018, 10, 2240. [CrossRef]

15. Bisno, H. Managing Conflict; Sage: Newbury Park, CA, USA, 1988.

16. Etxano, I.; Barinaga-Rementeria, I.; Garcia, O. Conflicting Values in Rural Planning: A Multifunctionality Approach Through Social Multi-Criteria Evaluation. Sustainability 2018, 10, 1431. [CrossRef]

17. Adams, W. Managing Tragedies: Understanding Conflict Over Common Pool Resources. Science 2003, 302, 1915-1916. [CrossRef] [PubMed]

18. Peterson, M.; Peterson, M.; Peterson, T.; Leong, K. Why Transforming Biodiversity Conservation Conflict Is Essential and How to Begin. Pac. Conserv. Biol. 2013, 19, 94. [CrossRef]

19. Barua, M.; Bhagwat, S.; Jadhav, S. The Hidden Dimensions of Human-Wildlife Conflict: Health Impacts, Opportunity and Transaction Costs. Biol. Conserv. 2013, 157, 309-316. [CrossRef]

20. Madden, F. Creating Coexistence Between Humans and Wildlife: Global Perspectives on Local Efforts to Address Human-Wildlife Conflict. Hum. Dimens. Wildl. 2004, 9, 247-257. [CrossRef]

21. Barlow, A.; Greenwood, C.; Ahmad, I.; Smith, J. Use of An Action-Selection Framework for Human-Carnivore Conflict in the Bangladesh Sundarbans. Conserv. Biol. 2010, 24, 1338-1347. [CrossRef]

22. Atran, S.; Axelrod, R. Reframing Sacred Values. Negotiat. J. 2008, 24, 221-246. [CrossRef]

23. Harich, F.; Treydte, A.; Sauerborn, J.; Owusu, E. People and Wildlife: Conflicts Arising Around the Bia Conservation Area in Ghana. J. Nat. Conserv. 2013, 21, 342-349. [CrossRef]

24. Jones, N.; McGinlay, J.; Dimitrakopoulos, P. Improving Social Impact Assessment of Protected Areas: A Review of the Literature and Directions for Future Research. Environ. Impact Assess. Rev. 2017, 64, 1-7. [CrossRef]

25. Mestanza, C.; Piccardi, M.; Pranzini, E. Coastal Erosion Management at Callao (Peru) in the 17Th and 18Th Centuries: The First Groin Field in South America? Water 2018, 10, 891. [CrossRef]

26. Angelsen, A. Measuring Livelihoods and Environmental Dependence; Taylor and Francis: Boca Raton, FL, USA, 2012.

27. McGregor, J. Researching Wellbeing: From Concepts to Methodology. In Well-Being in Developing Countries: New Approaches and Research Strategies; Cambridge University Press: Cambridge, UK, 2009; pp. 316-350.

28. Bonilla-Bedoya, S.; Estrella-Bastidas, A.; Molina, J.; Herrera, M. Socioecological System and Potential Deforestation in Western Amazon Forest Landscapes. Sci. Total Environ. 2018, 644, 1044-1055. [CrossRef]

29. Holland, M.; Jones, K.; Naughton-Treves, L.; Freire, J.; Morales, M.; Suárez, L. Titling Land to Conserve Forests: The Case of Cuyabeno Reserve in Ecuador. Glob. Environ. Chang. 2017, 44, 27-38. [CrossRef]

30. Granizo, T.; Molina, M.E.; Secaira, E.; Herrera, B.; Benítez, S.; Maldonado, Ó.; Libby, M.; Arroyo, P.; ïsola, S.; Castro, M. Manual de Planificación para la Conservación de Áreas, PCA; TNC y USAID: Quito, Ecuador, 2006.

31. Fernández-Vítora, V.C. Guía metodológica para la evaluación del impacto ambiental. Available online: http:/ / centro.paot.mx/documentos/varios/guia_metodologica_impacto_ambiental.pdf (accessed on 20 December 2018).

32. Bowd, R.; Quinn, N.; Kotze, D. Toward an Analytical Framework for Understanding Complex Social-Ecological Systems When Conducting Environmental Impact Assessments in South Africa. Ecol. Soc. 2015, 20, 41. [CrossRef]

33. Leopold, L.B.; Clarke, F.E.; Hanshaw, B.B.; Balsley, J.R. A Procedure for Evaluating Environmental Impact; U.S. Geological Survey: Washington, DC, USA, 1971.

34. Canteiro, M.; Córdova-Tapia, F.; Brazeiro, A. Tourism Impact Assessment: A Tool to Evaluate the Environmental Impacts of Touristic Activities in Natural Protected Areas. Tour. Manag. Perspect. 2018, 28, 220-227. [CrossRef]

35. Ander-Egg, E. Repensando la Investigacioón-Accioón-Participativa; Grupo Editorial Lumen/Hvmanitas: Buenos Aires, Argentina, 2003; ISBN 987000377X. 
36. SCDB-Secretaría Del Convenio Sobre La Diversidad Biológica. Directrices sobre Diversidad Biológica y Desarrollo del Turismo: Directrices Internacionales para Actividades Relacionadas con el Desarrollo del Turismo Sostenible en Ecosistemas Vulnerables, Terrestres, Marinos y Costeros y Hábitats de gran Importancia para la Diversidad Biológica y Áreas Protegidas, Incluidos los Ecosistemas Frágiles, Ribereños y de Montañas (Directrices del $C D B$ ); Secretaría del Convenio sobre la Diversidad Biológica: Montreal, QC, Canada, 2004; 30p.

37. Mitroff, I.I.; Turoff, M. Philosophical and methodological foundations of Delphi. In The Delphi method: Techniques and Applications; Addison-Wesley: Boston, MA, USA, 1975; pp. 17-35.

38. Daniel, M. Supervivencia al Desnudo Edición Extrema 2017 HD. 19 August 2017; [Video File]. Available online: https: / / www.youtube.com/watch?v=9hffDFaYYvg\&t=2309s (accessed on 28 November 2018).

39. Szalińska, E.; Orlińska-Woźniak, P.; Wilk, P. Nitrate Vulnerable Zones Revision in Poland-Assessment of Environmental Impact and Land Use Conflicts. Sustainability 2018, 10, 3297. [CrossRef]

40. Ye, Q.; Wei, R.; Zhang, P. A Conflict Identification Method of Urban, Agricultural and Ecological Spaces Based on the Space Conversion Matrix. Sustainability 2018, 10, 3502. [CrossRef]

41. Izakovičová, Z.; Miklós, L.; Miklósová, V. Integrative Assessment of Land Use Conflicts. Sustainability 2018, 10, 3270. [CrossRef]

42. Madden, F.; McQuinn, B. Conservation conflict transformation: The missing link in conservation. In Conflicts in Conservation: Navigating towards Solutions; Redpath, S.M., Gutiérrez, R.J., Wood, K.A., Young, J.C., Eds.; Cambridge University Press: Cambridge, UK, 2015; pp. 257-267. ISBN 9781107603462.

43. Büscher, B.; Fletcher, R. Accumulation by Conservation. New Political Econ. 2014, 20, 273-298. [CrossRef]

44. Frost, P.; Bond, I. The CAMPFIRE Programme in Zimbabwe: Payments for Wildlife Services. Ecol. Econ. 2008, 65, 776-787. [CrossRef]

(C) 2018 by the authors. Licensee MDPI, Basel, Switzerland. This article is an open access article distributed under the terms and conditions of the Creative Commons Attribution (CC BY) license (http:/ / creativecommons.org/licenses/by/4.0/). 